\title{
Investigation and analysis of ideological and political and moral status of university students in Xinjiang
}

\author{
Guixiang Sun
}

Shihezi University, Shihezi, 832003, China

\begin{abstract}
Keywords: University students in Xinjiang. Ideological and political. Moral education. Countermeasures and suggestions
\end{abstract}

\begin{abstract}
Grasp and understanding of university students' ideological and moral status and taking practical measures are of very significant importance for improving students' ideological and moral qualities and training qualified talents for socialist modernization construction. This study investigates the ideological, political and moral status of a total of 1,679 students from five universities in Xinjiang, and results show that the mainstream ideological and moral qualities of university students in Xinjiang are healthy and upward, but still have some problems that cannot be ignored.
\end{abstract}

\section{Introduction}

Ideological, political and moral education for university students has been key content of university education. Accurate and timely grasp and understanding of university students, ideological and moral status and taking targeted and practical measures are of very significant importance for improving students' ideological and moral qualities and training qualified talents for socialist modernization construction. This study aims at providing necessary basis of decision making for ideological and moral education of Xinjiang universities, by investigating the ideological, political and moral status of nearly 1,679 students from five universities in Xinjiang such as Xinjiang University and Shihezi University etc, and thus constantly enhance moral education for university students to be more scientific, targeted and effective in the new area.

\section{Respondents}

This study firstly uses typical sampling to select five universities (namely Xinjiang University, Shihezi University, Xinjiang Normal University, Yi Li Normal University and Hetian Normal Specialized Postsecondary College) in Xinjiang, and select different number of students randomly from each university. Questionnaire distribution and recovery are completed by head teachers, counselors and related personnel of each university. The sample size is 1,700, 1,679 questionnaires are recovered (recovery rate 98.7\%), and samples are general undergraduates and junior college students. Basic composition of samples is shown in table 1 :

Table 1. Basic Composition of Samples

\begin{tabular}{cccccc}
\hline & $\begin{array}{c}\text { Xinjiang } \\
\text { University }\end{array}$ & $\begin{array}{c}\text { Shihezi } \\
\text { University }\end{array}$ & $\begin{array}{c}\text { Xinjiang } \\
\text { Normal } \\
\text { University }\end{array}$ & $\begin{array}{c}\text { Yi Li Normal } \\
\text { University }\end{array}$ & $\begin{array}{c}\text { Hetian Normal } \\
\text { Specialized } \\
\text { Postsecondary College }\end{array}$ \\
\hline Freshmen & 70 & 70 & 70 & 70 & 70 \\
\hline Sophomore & 80 & 80 & 80 & 80 & 80 \\
\hline Junior & 80 & 80 & 80 & 80 & 70 \\
\hline Senior & 70 & 70 & 70 & 70 & 300 \\
\hline Total & 300 & 300 & 300 & 300 & 80 \\
\hline
\end{tabular}

\section{Results analysis and conclusions}

\section{Ideological and political cognition of university students in Xinjiang}

In table 2, when asking about "How do you think about the Scientific Outlook on Development is sustainable” , $92.5 \%$ of students agree, while $7.1 \%$ of students have little or no understanding. Data 
shows that university students support and understand national policies, and have significant ideological progress, and turn to concern about long-term social development, which is very good.

Table 2. How do you think about the Scientific Outlook on Development is sustainable

\begin{tabular}{cccccc}
\hline & Frequency & Percent & Valid Percent & $\begin{array}{c}\text { Cumulative } \\
\text { Percent }\end{array}$ \\
Valid & Completely agree & 1173 & 69.9 & 70.2 & 70.2 \\
& Agree & 379 & 22.6 & 22.7 & 92.8 \\
& Understand little & 91 & 5.4 & 5.4 & 98.3 \\
& Not understand & 29 & 1.7 & 1.7 & 100.0 \\
Missing & Total & 1672 & 99.6 & 100.0 & \\
Total & System & 7 & 4 & & \\
\hline
\end{tabular}

In table 3, for the understanding of current ethnic relations of university students from different ethnic groups, $31.21 \%$ of students select harmonious, $39.07 \%$ of students select basically normal, $14.65 \%$ of students select constant ethnic conflicts and emergencies may occur at any time, and only $0.95 \%$ of students select very prominent ethnic conflicts. This indicates that most students are increasingly rational and comprehensive in view of social problems such as ethnic relations etc, and could observe mainstream things, which is a very good thing.

Table 3. The understanding of current ethnic relations of university students from different ethnic

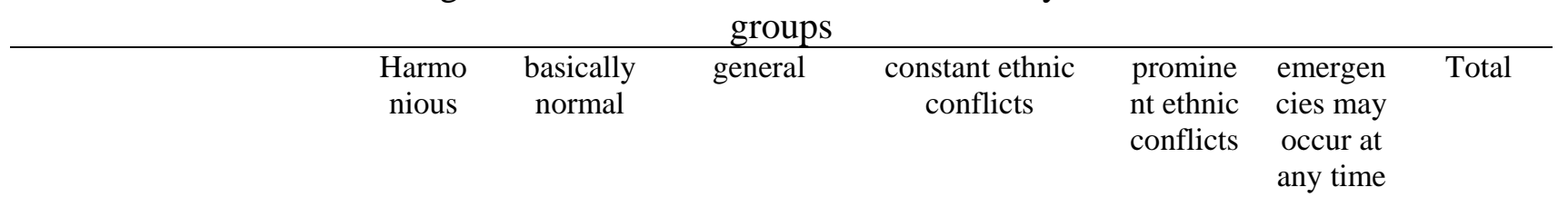

\begin{tabular}{|c|c|c|c|c|c|c|c|c|}
\hline Nationalit & Han & 139 & 345 & 80 & 101 & 7 & 23 & 695 \\
\hline \multirow[t]{4}{*}{$\mathrm{y}$} & Uighur & 341 & 237 & 85 & 73 & 9 & 18 & 763 \\
\hline & Kazak & 24 & 45 & 12 & 14 & & 3 & 98 \\
\hline & Hui & 5 & 16 & 4 & 8 & & 1 & 34 \\
\hline & Others & 15 & 13 & 3 & 4 & & 1 & 36 \\
\hline Total & & 524 & 656 & 184 & 200 & 16 & 46 & 1626 \\
\hline
\end{tabular}

In table 4, when asking about “The most influencing social factor of university students' ideological fluctuations” , about $42.6 \%$ of students select employment situation, followed by social thought, which is selected by $25.7 \%$ of students. Natural disasters, traditional cultures, emergencies and economic situation have little influence. Thus, universities and the society shall attach great importance to employment factor and social thought, and create actively good employment environment and promote positive social thought.

Table 4. What do you think is the most influencing social factor of university students' ideological

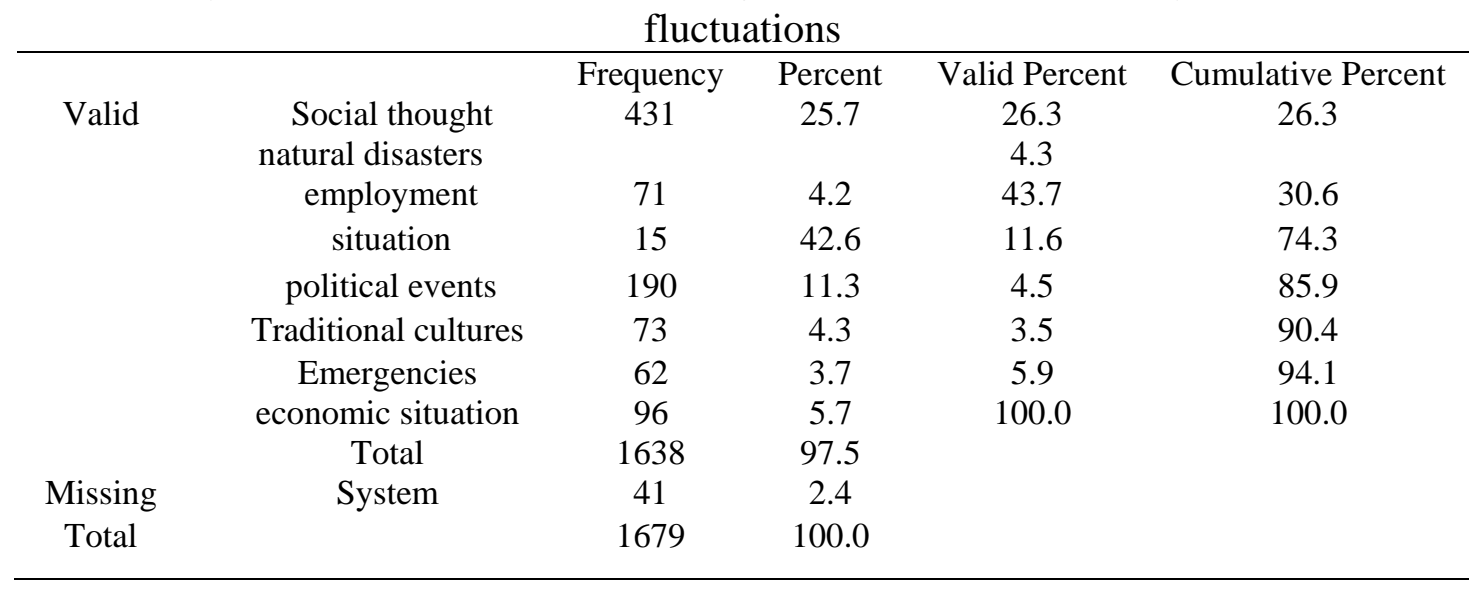




\section{Moral cognition of university students in Xinjiang}

In table 5, in terms of "Honesty" , when asking about the necessity of being honest, 64.7\% of students select completely necessary, and $29 \%$ of students select sometimes necessary, which means that sometimes unnecessary, making it depends. This means that they would be honest when there is supervision or stake, otherwise, they would not be honest, which is risky and opportunistic.

Table 5. Being honest

\begin{tabular}{cccccc}
\hline & & Frequency & Percent & Valid & Cumulative \\
Percent & $\begin{array}{c}\text { Percent } \\
\text { Valid }\end{array}$ & & & 64.7 & 64.7 \\
& Completely necessary & 1076 & 64.1 & 29.0 & 93.7 \\
& Sometimes necessary & 483 & 28.8 & 4.0 & 97.8 \\
& Unnecessary & 67 & 4.0 & 2.2 & 100.0 \\
Missing & Doesn't matter & 37 & 2.2 & 100.0 & \\
Total & Total & 1663 & 99.0 & & \\
\hline
\end{tabular}

In table 6, when asking about "Would you help your class

mates who are in trouble" , 89.8\% of students are very willing to, indicating that contemporary university students are willing to try their best to help others and be high-quality social people while improving their skills.

Table 6. Would you help your classmates who are in trouble

\begin{tabular}{cccccc}
\hline & & Frequency & Percent & Valid & Cumulative \\
Percent & Percent \\
Valid & Very willing & 1491 & 88.8 & 89.8 & 89.8 \\
& Unwilling & 84 & 5.0 & 5.1 & 94.8 \\
& Doesn' t matter & 86 & 5.1 & 5.2 & 100.0 \\
Missing & Total & 1661 & 98.9 & 100.0 & \\
Total & System & 18 & 1.1 & & \\
\hline
\end{tabular}

\section{Moral behaviors of university students in Xinjiang}

In table7, in the survey of "Donation" among university students, regardless of gender and grade, university students generally participate in social donation actively, which reflects that university students have loving hearts and a strong sense of social responsibilities to a certain degree. We shall advocate these behaviors vigorously, to achieve the sayings "every man alive has a duty to his country" and "in success, one tries to let others be benefited" .I

Table 7. Grade* donation behaviors*gender

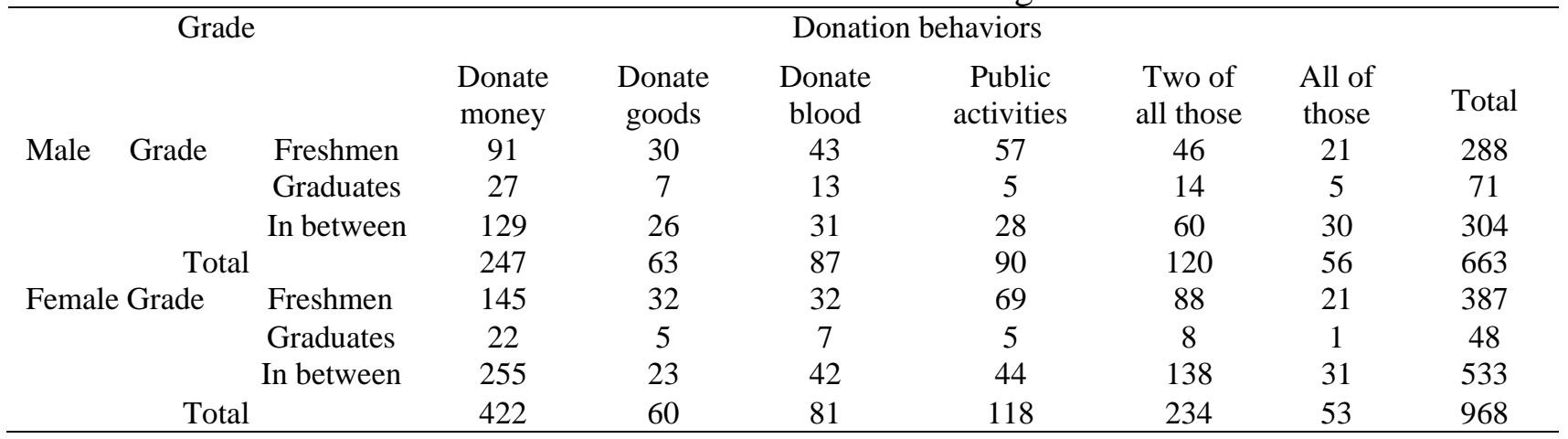

In table 8, when asking about "In what way do you usually help others" , the top three answers include economy, learning and life which account for 33.4\%, 32.5\% and 16.6\% respectively. 1.9\% of students never help others or ask for help. This indicates that contemporary university students have loving hearts, and wish to get help from whom they help, as we are one member of the unity of various social relations. 
Table 8. In what way do you usually help others

\begin{tabular}{cccc}
\hline Name & Count & Responses & Cases \\
Economy & 555 & 33.4 & 33.6 \\
Learning & 540 & 32.5 & 32.7 \\
Life & 276 & 16.6 & 16.7 \\
Psychology & 260 & 15.6 & 15.7 \\
Never help & 18 & 1.1 & 1.1 \\
Never ask for & 13 & 0.8 & 0.8 \\
help & 13 & & 0.8 \\
\hline
\end{tabular}

In table 9 , in terms of politeness, $69.9 \%$ of university students often use daily civilized language and a small number of students never or feel difficult to say. As cutting-edge talents, university students shall have high-quality speech and behaviors. We shall develop good daily habits, be polite and civilized, and form a habit of being polite.

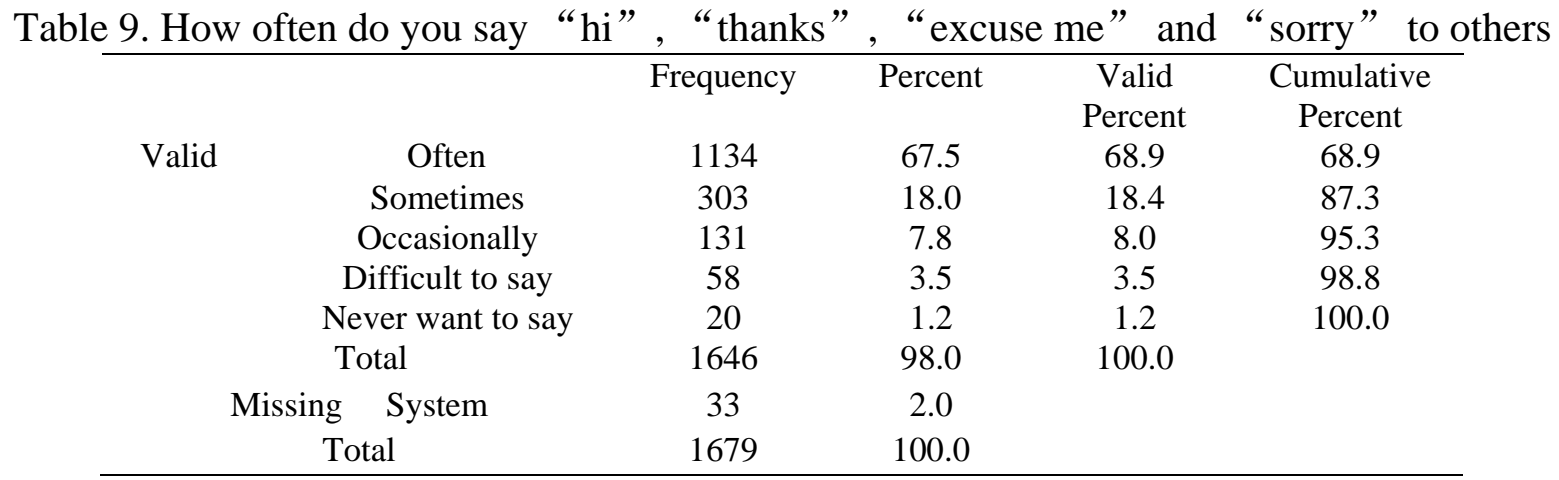

\section{Basic evaluation of ideological, political and moral status of university students in Xinjiang}

1). According to results of above data analysis, most students in Xinjiang universities have clear political views and strong political awareness, love the party and motherland and socialism, support consciously the party' $\mathrm{s}$ leadership, routes, guidelines and policies, view dialectically Marxism-Leninism and Mao Zedong Thought etc, and have a positive and confident attitude towards China' s development situation, building a moderately prosperous society and a harmonious society; however, they have not enough knowledge and understanding of some aspects, especially in multi-ethnic areas, it is very necessary to know about relevant ethnic policies and regulations, and these aspects shall be further strengthened in university ideological and political education. According to analysis of moral cognition and behaviors of university students in Xinjiang, the mainstream morality of current university students is healthy and upward, and most students regard "love the motherland", "honest and trustworthiness" , " self-esteem, self-respect and self-love" , "a sense of responsibility" and "helpful” as excellent qualities of a person and shall put into practice; however, some students do not have a correct understanding of moral values, and declare to be individual-centered and personal interests come first. Thus, universities shall pay attention to this issue during moral education, so that students could have a correct ideological understanding and would put into practice.

2). From a macroscopic perspective, the evolution path of university students' ideology is mainly from traditional "single and stable" and "conscious and faithful" to "multiple and utilitarian" . From a microscopic perspective, university students' ideological changes are more complex. Because of diversified ethnic cultures and customs and imbalanced regional economic development of Xinjiang, besides general characteristics of ideological status like mainland university students, ideology of university students in Xinjiang has distinctive features.

3). In Xinjiang universities, minority students account for a large proportion, which is the particularity of objects of ideological and political work of Xinjiang universities. Therefore, to have targeted discussion on the influence of domestic and foreign political environment on ideological and political education of university students in Xinjiang, the ideological status of minority students shall 
be studied seriously and in detail. The ideological status of minority university students in the new era shall be analyzed from the following two aspects:

\section{Positive aspects}

1). Exchanges of minority students with Han students are further deepened. Minority and Han students strengthen communication about languages, customs and cultures in common life and learning environment, enhance their understanding and communication, and eliminate psychological barriers among different ethnic groups. Although their communication is affected by language barriers to a certain extent, minority students still show positive enthusiasm for exchanging with Han students, and hope to contact with and learn from Han students in order to improve their qualities and Mandarin proficiency.

2). Minority university students have an increasingly profound understanding that the stability and economic prosperity of Xinjiang cannot be separated from harmony among ethnic groups during Western Development, and shall understand each other, and learn from others' strengths to offset their weaknesses. They know deeply that the development course of Xinjiang is a history of mutual integration and common progress of all ethnic groups. Facing current historical opportunity of Western Development, national unity is even more important.

\section{Negative aspects}

1). Restricted by environmental conditions, some minority students have a narrow ethnic consciousness. For example, some minority students are unwilling to communicate with Han students in terms of thoughts and knowledge etc. Driven by closed ethnic self-consciousness and narrow ethnic sentiment, they seek to maximize ethnic interests unilaterally and exclude interests of other ethnic groups. Such thoughts seriously hinder normal exchanges and communication between minority and Han students, and are not only incompatible with new socialist ethnic relations that we advocate, but also seriously undermine the stability and unity of Xinjiang and hinder Xinjiang economic development.

2). The influence of overseas "Three Evils" on some university students. In recent years, ethnic separatists carry out reactionary publicity aiming at splitting the motherland, and undermine ethnic unity and social stability of Xinjiang. They take minority university students as main objectives. Under the influence of these "Three Evils" , some minority university students change their position, and even embark on the road of subverting the country and affecting the stability of Xinjiang.

\section{Acknowledgments}

This article is in 2010 the national social science fund project "the Xinjiang ethnic identity of ethnic college students with harmonious national relations research" (10CSH007).

\section{References}

[1] S. K. Goyal, An integrated inventory model for a single supplier-single customer problem, International Journal of Production Research, vol.15, pp. 107-111, 1977.

[2] Chen Lu. On the ideological and political education of the school of administration effectively guide, Liaoning Journal of education.2010 (03)

[3] Shen Shuguang, Li Shaohua. The innovation of Ideological and political education work, Chinese Rural Health Service Administration . 2009 (09)

[4] Yang Zhanwen. Countermeasure thought of contemporary college students' outlook on life education, Career Horizon.2007 (16)

[5] Xu Feng. The perspective of harmonious campus in college students' ideological and political education action research, University of South China, 2010.

[6] Liu Shaoying .Introduction to contemporary college students' ideological and political education, Legal System and Society .2009 (35) 